\title{
On the original author and year of description of the extinct hyaenid Pachycrocuta brevirostris
}

\author{
David M. Alba, Víctor Vinuesa, and Joan Madurell-Malapeira \\ Acta Palaeontologica Polonica 60 (3), 2015: 573-576 doi:http://dx.doi.org/10.4202/app.00017.2013
}

The International Code of Zoological Nomenclature recommends providing the author and year of original description of any taxon when first mentioned in a publication, which is useful for both taxonomic and nomenclatural reasons. Here we show that the authorship of the extinct hyaenid taxon Hyaena brevirostris, type species of the genus Pachycrocuta, has been incorrectly attributed to "Aymard, 1846" for more than a century on the basis of a publication that never existed. Our bibliographic research indicates that the first published work in which the name was employed-Gervais' (1848-1852) Zoologie et Paléontologie françaises, the part dealing with carnivorans being issued in 1850-fulfils the criteria of availability. Given that Gervais did not attribute the description to Aymard, but merely employed the latter's name in reference to a museum label/record (which does not constitute a valid indication), the correct name with authorship for this taxon is Pachycrocuta brevirostris (Gervais, 1850).

David M. alba [david.alba@icp.cat], Institut Català de Paleontologia Miquel Crusafont, Edifici ICP, Campus de la UAB s/n, 08193 Cerdanyola del Vallès, Barcelona, Spain; and Dipartimento di Scienze della Terra, Università di Torino. Via Valperga Caluso 35, 10125 Torino, Italy; Víctor Vinuesa [victor.vinuesa@icp.cat ] and Joan Madurell-Malapeira [joan.madurell @icp.cat], Institut Català de Paleontologia Miquel Crusafont, Edifici ICP, Campus de la UAB s/n, 08193 Cerdanyola del Vallès, Barcelona, Spain.

This is an open-access article distributed under the terms of the Creative Commons Attribution License (for details please see creativecommons.org), which permits unrestricted use, distribution, and reproduction in any medium, provided the original author and source are credited. 
FoF Full text $(192.2 \mathrm{kB})$ 